DOE/SC-ARM/P-07-002.5

\title{
ACRF Instrumentation Status: New, Current, and Future
}

May 2007

James Liljegren

ACRF Instrument Team Coordinator

Work supported by the U.S. Department of Energy,

Office of Science, Office of Biological and Environmental Research 


\section{Summary}

The purpose of this report is to provide a concise but comprehensive overview of Atmospheric Radiation Measurement Program Climate Research Facility instrumentation status. The report is divided into four sections: (1) new instrumentation in the process of being acquired and deployed, (2) existing instrumentation and progress on improvements or upgrades, (3) proposed future instrumentation, and (4) Small Business Innovation Research instrument development. New information is highlighted in blue text. 



\section{Contents}

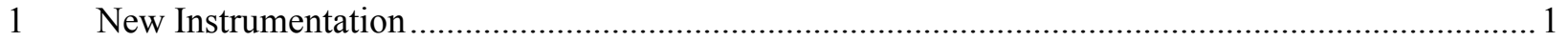

1.1 Thin Cloud Rotating Shadowband Radiometer (TC-RSR) for LWP, $\mathrm{r}_{\text {eff }}$, and $\tau_{\text {cloud }} \ldots \ldots \ldots \ldots \ldots . . . . . .1$

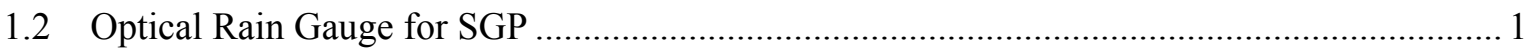

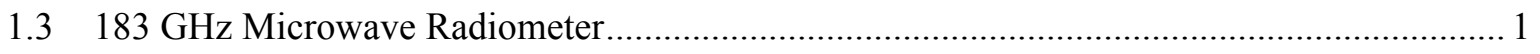

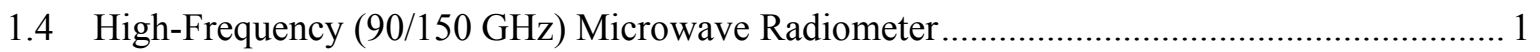

1.5 Infrared Sky Imager................................................................................................. 2

1.6 Add Multi-Filter Radiometers to Cessna 206 (In-situ Aerosol Profiling aircraft) ................... 2

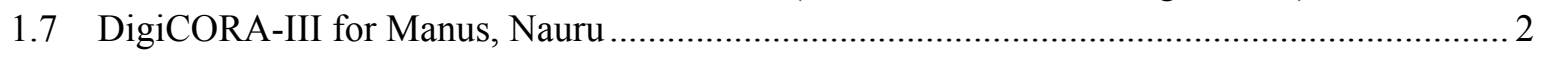

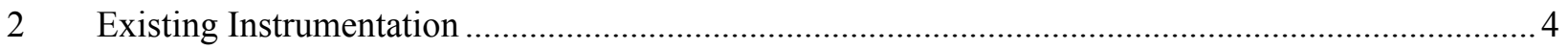

2.1 Atmospherically Emitted Radiance Interferometer ............................................................. 4

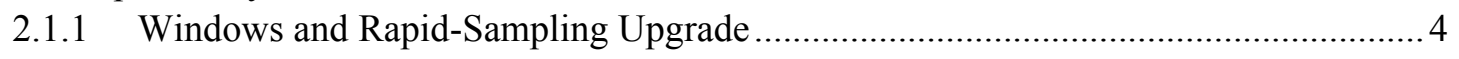

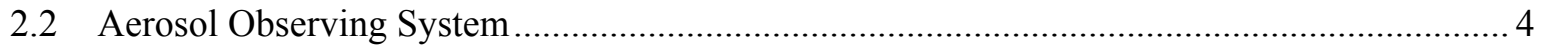

2.2.1 Reconfigure Southern Great Plains Aerosol Observing System ............................... 5

2.3 Balloon-Borne Sound System ...................................................................................... 5

2.3.1 Make Atmospheric Radiation Measurement Program-Barrow Soundings

Available to the Global Telecommunication System .............................................. 5

2.4 Broadband Radiometers (SIRS, SKYRAD, GNDRAD, BRS) …...................................... 5

2.4.1 Pyrgeometer Calibration Improvements ......................................................... 6

2.4.2 Radiometer Calibration Facility Data Acquisition System Replacement

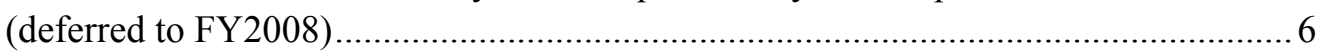

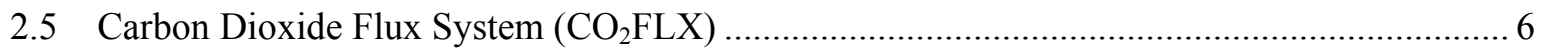

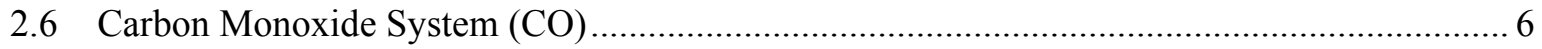

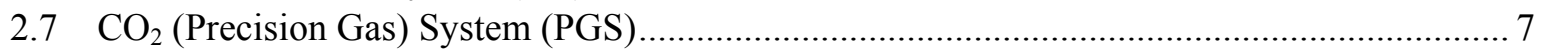

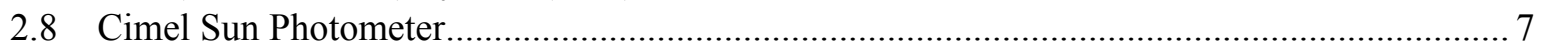

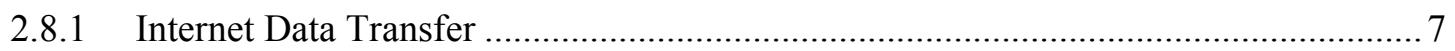

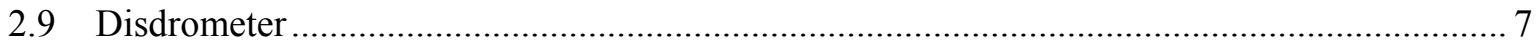

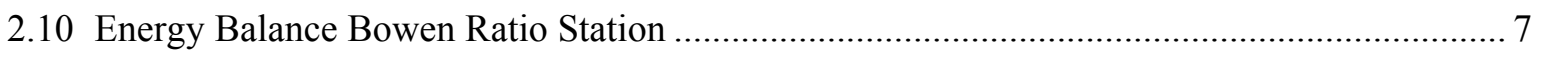

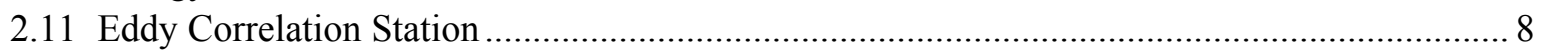

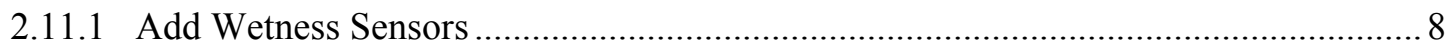

2.12 G-Band (183.3 GHz) Water Vapor Radiometer .......................................................... 8

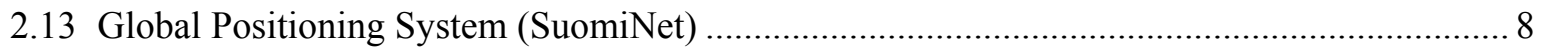

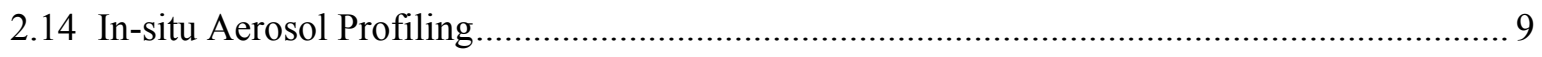

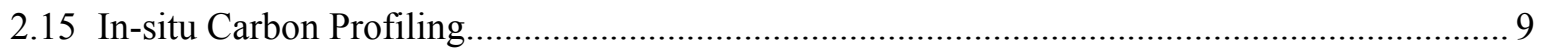

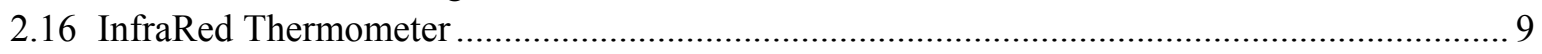

2.17 Multi-Filter Rotating Shadowband Radiometer and Related Systems (MFR, GNDMFR, NIMFR).

2.17.1 Multi-Filter Rotating Shadowband Radiometer Calibration and Data Processing

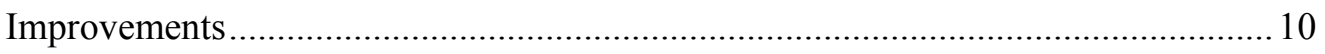

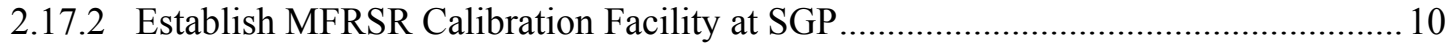

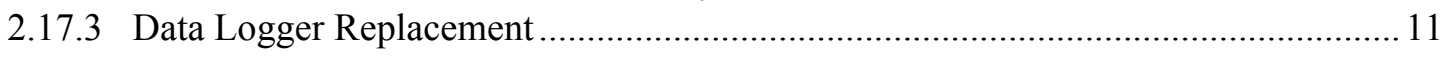

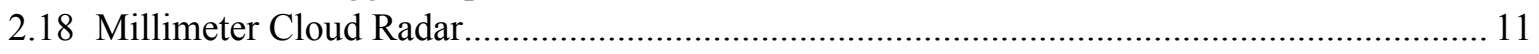

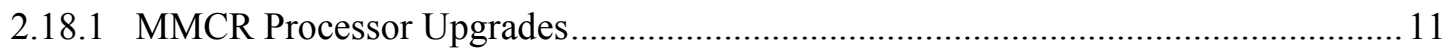

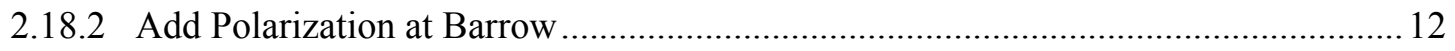

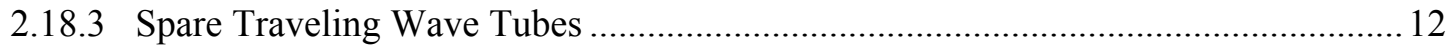


2.18.4 Millimeter Wave Cloud Radar Spectra Processing …............................................. 12

2.18.5 Refurbish Millimeter Wave Cloud Radar Antennas ............................................... 12

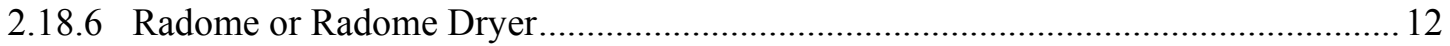

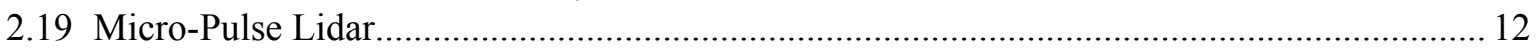

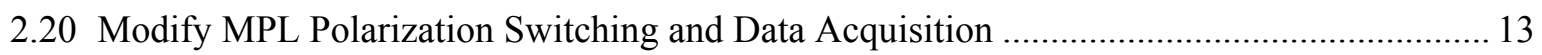

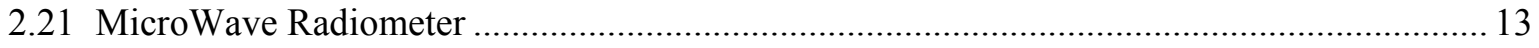

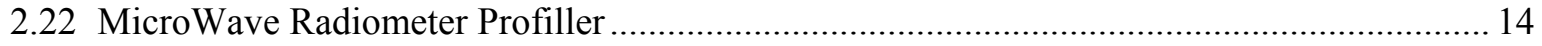

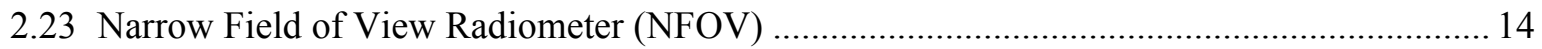

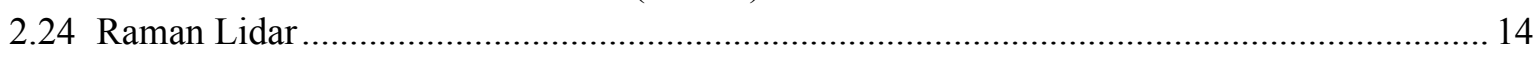

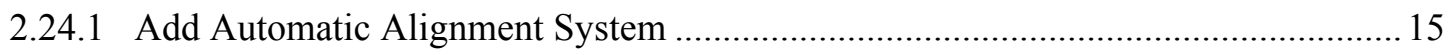

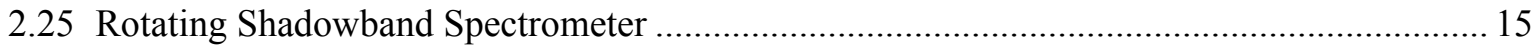

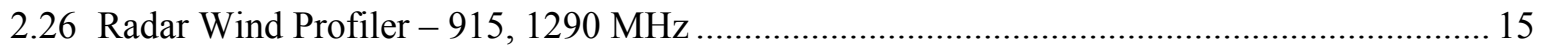

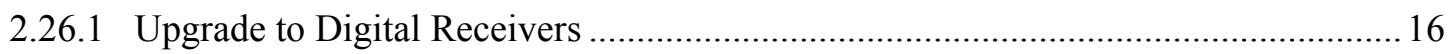

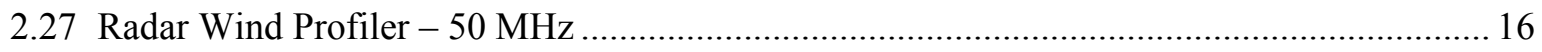

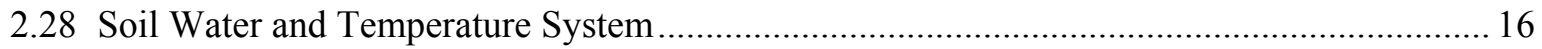

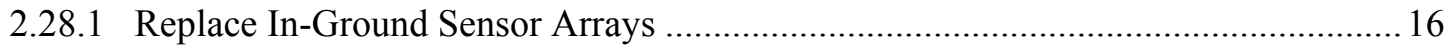

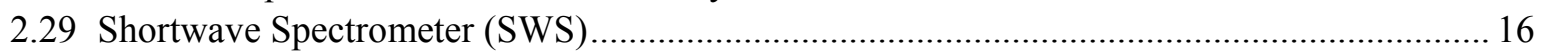

2.30 Surface Meteorological Instrumentation (SMET, SMOS, SURTHREF, THWAPS,

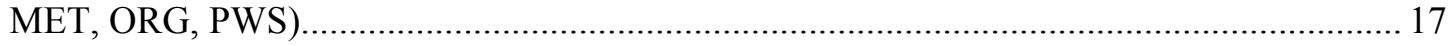

2.30.1 Develop Dynamic Rain Gauge Calibration Facility .............................................. 17

2.30.2 Upgrade T/RH Probes and Wind Sensors for NSA Met Systems ............................. 17

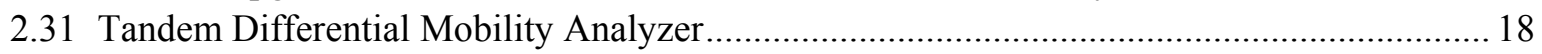

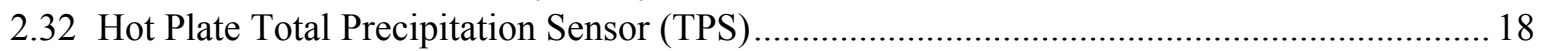

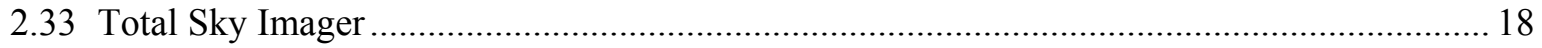

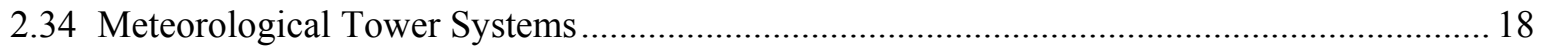

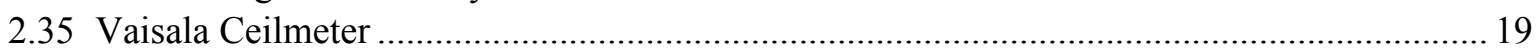

2.36 W-band (95 GHz) Atmospheric Radiation Measurement Program Cloud Radar .................. 19

2.36.1 Study Network Transfer of MMCR and WACR Spectra to Archive......................... 19

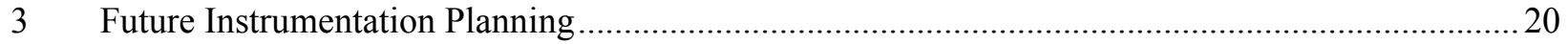

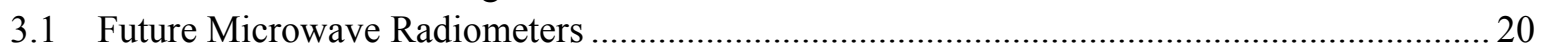

3.2 Atmospheric Radiation Measurement Program Volume-Imaging Array ............................... 20

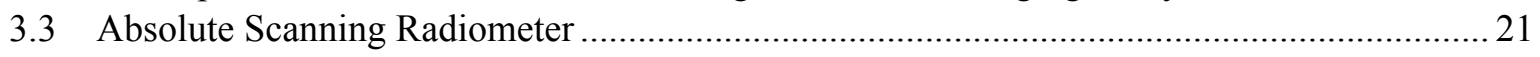

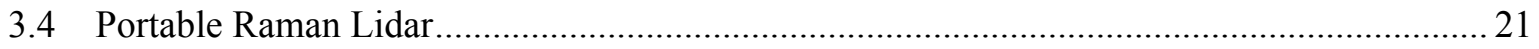

3.5 High-Resolution Oxygen A-Band and Water-Band Spectrometer........................................ 21

3.6 Rotating Shadowband Spectrometer Overhaul .............................................................. 21

3.7 Add 1.6 :m Channel to Multi-Filter Rotating Shadowband Radiometer and

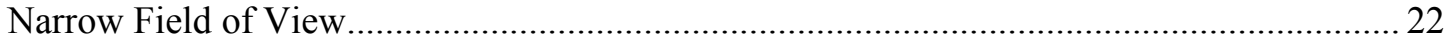

3.8 Aerosol Particle Sizing Spectrometer to Replace Optical Particle Counter at

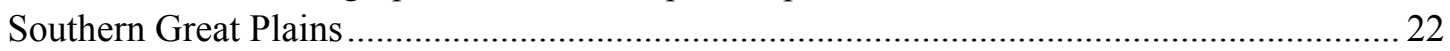

3.9 Aerosol Particle Sizing Spectrometer (APS) to Replace Optical Particle

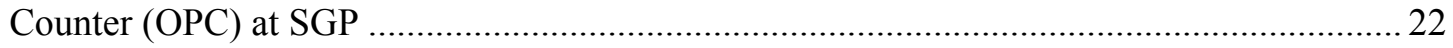

3.10 Infrared Thermometers for the Southern Great Plains Extended Facility Sites ..................... 22 
$4 \quad$ Small Business Innovation Research 23

4.1 Eye-Safe Ultraviolet Backscatter Lidar for Detection of Sub-visual Cirrus (FY 2006)......... 23

4.2 Instrumentation for Remotely Sensing Aerosol Optical Properties -

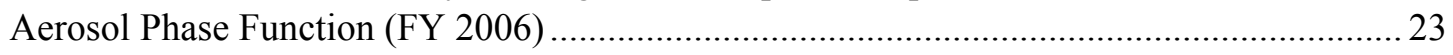

4.3 Unmanned Aerospace Vehicle-Suitable Cloud Radar (FY 2006)....................................... 23

4.4 In-situ Measurement of Cloud Properties with Large Sample Volumes (FY 2007) ............... 23 


\section{New Instrumentation}

\subsection{Thin Cloud Rotating Shadowband Radiometer (TC-RSR) for LWP, $\mathrm{r}_{\mathrm{eff}}$, and $\tau_{\text {cloud }}$}

Andy Vogelmann and Mike Reynolds will modify an existing Brookhaven National Laboratory Fast Rotating Shadowband Radiometer (FRSR) to enable Qilong Min to apply his algorithms to retrieve liquid water path, visible optical depth, and effective radius for thin clouds. Although Andy and Mike had hoped to complete this work in time for deployment at the AMF site in Germany or during the CloudLand Surface Interaction Campaign (CLASIC) at SGP in June 2007, the delay due to the Continuing Resolution prevented this. The TC-RSR will remain a BNL-owned instrument, with additional costs to ACRF for each IOP deployment for field operation and data reduction.

\subsection{Optical Rain Gauge for SGP}

An optical rain gauge will be acquired for the SGP for use with the Atmospheric Remotely Sensed Cloud Boundaries (ARSCL) value-added procedure (VAP). The AMF and TWP field sites already have optical rain gauges installed. (ECO-00621)

\section{3 $183 \mathrm{GHz}$ Microwave Radiometer}

Radiometrics Corporation has proposed to deploy at North Slope of Alaska (NSA)-Barrow a new $183 \mathrm{GHz}$ microwave radiometer that they have developed under a U.S. Department of Energy (DOE) Small Business Innovation Research (SBIR) grant (ECO-00609). The radiometer worked well during the Radiative Heating in Under-explored Bands Campaign (RHUBC).

STATUS - The radiometer deployment has been extended to permit additional comparisons with the NOAA Ground-based Scanning Radiometer (GSR) that was also deployed during RHUBC.

\subsection{High-Frequency $(90 / 150 \mathrm{GHz})$ Microwave Radiometer}

Mentor: Maria Cadeddu, Argonne National Laboratory

In response to the need for greater sensitivity (and therefore higher frequency) microwave channels to more accurately measure liquid water paths in thin clouds than the current $23.8 / 31.4 \mathrm{GHz}$ instruments permit, a new High-Frequency Microwave Radiometer (MWRHF) has been acquired, and is currently deployed at Southern Great Plains (SGP) (ECO-00491).

STATUS - A hardware failure occurred in the $150 \mathrm{GHz}$ channel. The instrument has been repaired and shipped to SGP. It will be reinstalled in early June.

CORRECTION: The second instrument was NOT deployed at Heselbach, Germany in April as reported previously. Installation is now scheduled for the week of 4 June. 


\subsection{Infrared Sky Imager}

Mentor: Vic Morris, Pacific Northwest National Laboratory

An infrared (IR) sky imager from Blue Sky Imaging (http://www.aas.org/career/bluesky.html) was deployed at SGP in September 2005 to provide nighttime cloud cover measurements (ECO-00429). Problems with moisture infiltration of the imager necessitated its return to the manufacturer for repair/revision in October 2005. The unit was returned to SGP in late June 2006 and returned to service in August 2006. In late January 2007 SGP technicians resolved hardware problems and restored the IRSI to operation. Software modifications by the manufacturer have corrected the image mask problem, which has permitted cloud fraction to be derived from the images. In February 2007 Vic Morris conducted a comparison of cloud fractions from the IRSI and the TSI. The comparisons indicate the IRSI is still not producing correct cloud fractions.

STATUS - Vic is looking into the Solmirus All Sky Infrared Visible Analyzer (www.solmirus.com/home/index.php?section=ASIVA), developed for the Large Synoptic Survey Telescope site, as an alternative to the BSI ASTIC and the Heitronics Nubiscan. The Solmirus unit appears to have the required specifications, including four IR bandwidths, and provides hemispheric images and measurements of cloud fraction and temperature at a time resolution of 8 seconds.

\subsection{Add Multi-Filter Radiometers to Cessna 206 (In-situ Aerosol Profiling aircraft)}

Currently, spectral albedo measurements are only possible at the SGP central facility using downward facing Multi-Filter Radiometers (MFR) on the 25-m level of the 60-m tower over a wheat field, and on a 10-m tower over the adjoining pasture. By adding a MFR to the Cessna 206 used for the In-situ Aerosol Profile (IAP), routine measurements of surface spectral albedo could be acquired over a broader area around the SGP central facility (ECO-00584).

STATUS - The Cessna 206 has returned to Ponca City from Wichita where the extended wingtips and MFR instrument were installed and approved. Greenwood Aviation has installed the in-wing cable to the MFR. A shelf to fit in the port side aft instrument rack was fabricated at NOAA to hold the Campbell CR1000 data logger, the power supply, and the heater control unit. It was wired and tested at NOAA using another MFR then sent to Ponca City for installation on the aircraft in time for the CLASIC/CHAPS field programs in June 2007. John Schmelzer met with Greenwood Aviation during his visit to SGP the week of 21 May. John noticed that the MFR installation needs to be modified so that the artificial horizon is flush with the wing surface rather than recessed about 3/4 inches. Greenwood Aviation is making the modifications. John also assembled and tested the data logging system using the MFR installed in the aircraft.

\subsection{DigiCORA-III for Manus, Nauru}

Mentor: Barry Lesht, Argonne National Laboratory

The digiCORA is the ground station for the Vaisala balloon borne sounding system. In FY 2003-2004 new digiCORA-III systems were acquired and deployed at SGP-Central Facility (CF), NSA-Barrow, and AMF as the primary ground station for those sites. For reliability and compatibility reasons it is necessary to replace the digiCORA-II systems at Manus and Nauru with the new digiCORA-III systems (ECO-00598). 
STATUS - Installation of the new digiCORA-III on Nauru has been delayed until the August RESET visit. A new digiCORA-III will be installed on Manus in June, after the necessary antenna upgrade kit is acquired. The old digiCORA-II systems will not be used as spares; they will be returned to the SGP. 


\section{Existing Instrumentation}

This section describes the current status of the existing instrumentation, including any upgrades planned or in progress. The information is abstracted primarily from the Instrument Mentor Monthly Summary reports (available from the instrument web pages) and from ECO status updates.

\subsection{Atmospherically Emitted Radiance Interferometer}

Mentor: Dave Turner, Space Science and Engineering Center, University of Wisconsin

AMF (Heselbach) - Operating nominally. It is using the original OS/2-based electronics rack that was used at Niamey due to a failure in the WINDOWS-based electronics. In order to reduce the size of the AMF "footprint", relocating the AERI to the Aerosol Trailer is under discussion.

NSA (Barrow) - This Windows XP-based AERI is operating nominally. The hatch controller is not correctly reporting the hatch state (open/closed).

SGP - Both the Windows XP-based and OS/2-based AERIs are operating nominally.

TWP (Darwin) - This Windows XP-based AERI is operating nominally.

TWP (Nauru) - This Windows XP-based AERI is operating nominally.

\subsubsection{Windows and Rapid-Sampling Upgrade}

Migration of the AERI software from OS/2 Warp to Windows XP and related computer hardware modernization to enable rapid sampling of the IR spectrum at 10-s intervals was begun in FY2004 (ECO00286). Upgraded AERI systems are currently operational at SGP, NSA-Burrow, and Tropical Western Pacific (TWP)-Nauru, and TWP-Darwin.

STATUS - An upgraded electronics rack and Windows XP computer were shipped to Germany to replace the old OS/2 electronics rack used with the AMF AERI system. Unfortunately the electronics subsystem failed in transit to Germany and has been returned to SSEC for diagnosis and repair. An upgraded AERI was successfully installed at Darwin in mid-April.

\subsection{Aerosol Observing System}

Mentor: John Ogren and Anne Jefferson, NOAA/ESRL/GMD

AMF (Heselbach) - In March Anne Jefferson traveled to Heselbach, Germany to install the AOS as part of the AMF deployment. Data collection started on 24 March. For the first two weeks of operation the data show the site to be fairly polluted for a rural setting. A replacement DVD/CD drive has been sent because the current drive occasionally malfunctions.

SGP - Anne Jefferson traveled to SGP 14 -25 May to reconfigure the AOS and its data system. The system was down from 15-22 May during the rebuild; it was returned to service on 23 May. The AOS system is currently logging in the new data format. 


\subsubsection{Reconfigure Southern Great Plains Aerosol Observing System}

The aerosol observing system (AOS) at SGP will be reconfigured to have similar components and data acquisition system as the aerosol systems for AMF, NSA, and the IAP aircraft measurements over the SGP (ECO-00569).

STATUS - This work has been completed.

\subsection{Balloon-Borne Sound System}

Mentor: Barry Lesht, Argonne National Laboratory

Overall radiosonde data recovery was excellent during April, with sounding reporting rates of FKB 115/120 (96\%), NSA 55/60 (92\%), SGP 114/120 (95\%), TWP/C1 (Manus) 56/60 (93\%), and TWP/C2 (Nauru) 47/60 (78\%). Normal operations at TWP/C2 were curtailed because of a failure of the hydrogen generator. This required using a backup supply of helium and cutting back on the frequency of soundings. Regular AMF operations in Germany (FKB) began in April.

Some of the differences between the surface values of temperature pressure, and humidity and the first values after launch are much larger than would expected, especially at TWP, which is the only site where the surface values are entered by hand by the operators.

\subsubsection{Make Atmospheric Radiation Measurement Program-Barrow Soundings Available to the Global Telecommunication System}

January 2007 - Soundings from SGP and NSA (Barrow) are now available to the global telecommunications system (GTS). Soundings from TWP (Manus and Nauru) will also be available to the GTS once the new DigiCORA-III systems are installed and operational there.

\subsection{Broadband Radiometers (SIRS, SKYRAD, GNDRAD, BRS)}

Mentor: Tom Stoffel, National Renewable Energy Laboratory

SGP/BORCAL 2007-01 is in progress by Site Operations and NREL team. Data collection is continued during clear sky conditions in May. BORCAL reports and reference irradiance data for all 11 years of radiometer calibrations at the SGP Radiometer Calibration Facility are now available at http://www.nrel.gov/srrl/borcal.html.

SIRS (24@SGP) and BRS (1@SGP) - Data for April 2007 were generally excellent with 100\% data collection except at E16 (86\%) and E27 (62\%) due to communication problems between the data system computers and the SIRS data logger. Of the 1-minute irradiance data collected, more than $97 \%$ of the shortwave and $100 \%$ of the longwave data passed automated data quality tests. "Failed" shortwave (solar) data are generally limited to low irradiances (less than $300 \mathrm{~W} / \mathrm{sq} \mathrm{m}$ ) at high solar zenith angles or can be attributed to the varying thermal offsets and time responses of the thermopile-based radiometers to rapidly changing sky conditions, e.g. cloud cover and water vapor concentrations.

SKYRAD/GNDRAD (3@TWP, 2@NSA, 1@AMF)-Downwelling broadband solar and atmospheric irradiances (SKYRAD) data for March 2007 were excellent with 100\% data collection at all stations 
(NSA, and TWP). Of the 1-minute irradiance data collected, at least $99 \%$ of the shortwave and $100 \%$ of the longwave data passed automated data quality tests. At Heselbach, Germany the effects of the slightly restricted solar access by the surrounding mountains are apparent for about 1.5 hours prior to and following local geometric sunrise and sunset. Upwelling shortwave is suppressed as is the surface heating during these periods.

\subsubsection{Pyrgeometer Calibration Improvements}

Tom Stoffel and Ibrahim Reda have initiated an investigation into the source of the bias in the ACRF pyrgeometer blackbody calibration system. (ECO-00559). At blackbody temperatures less than $-20^{\circ} \mathrm{C}$, the Dow Corning 200 fluid viscosity increases, which inhibits mixing and results in a temperature gradient of $3^{\circ} \mathrm{C}$ from the base to the top of the hemispherical blackbody. A new set of fluid dispersion manifolds (perforated annuli) has been developed to reduce the temperature gradients in the blackbody. Additionally, a replacement fluid with better low-temperature (viscosity) characteristics has been identified. Pyrgeometers calibrated using the new manifold and fluid will be compared with pyrgeometers having calibrations traceable to the World Infrared Standard Group (WISG) and with pyrgeometers calibrated by NOAA/GMD.

STATUS - Reda has replaced the fluid in the Pyrgeometer Blackbody Calibration System at NREL with a new Dow fluid that offers better low temperature performance and provides more 6 uniform blackbody temperature control. Preliminary data suggest the $3{ }^{\circ} \mathrm{C}$ temperature difference between the top of the blackbody hemisphere and the $45^{\circ}$ elevation at $-30^{\circ} \mathrm{C}$ is now less than $1^{\circ} \mathrm{C}$. Reda continues to explore methods for confirming/correcting this lower $\Delta \mathrm{T}$.

\subsubsection{Radiometer Calibration Facility Data Acquisition System Replacement (deferred to FY2008)}

The data acquisition system in the Radiometer Calibration Facility used for annual Broadband Outdoor Radiometer Calibration (BORCAL) activities is over ten years old and needs to be updated. NREL has recently replaced their BORCAL data acquisition system using internal funds. The SGP system should be a duplicate of the NREL system for software compatibility and performance assurance.

\subsection{Carbon Dioxide Flux System $\left(\mathrm{CO}_{2} \mathrm{FLX}\right)$}

Mentor: Marc Fischer, Lawrence Berkeley National Laboratory

The $\mathrm{CO}_{2} \mathrm{FLX}$ instruments at 4, 25, and $60 \mathrm{~m}$ on the SGP-CF tower are operating nominally. Problems with the net radiometers have been corrected.

\subsection{Carbon Monoxide System (CO)}

Mentor: Sébastien Biraud, Lawrence Berkeley National Laboratory

Nothing to report. 


\title{
$2.7 \quad \mathrm{CO}_{2}$ (Precision Gas) System (PGS)
}

\author{
Mentor: Margaret Torn and Sebastien Biraud, Lawrence Berkeley National Laboratory
}

A comparison of PGS CO2 measurements against NOAA flasks and isotope flasks collected at all heights of the $60-\mathrm{m}$ tower shows a difference on the order of $1 \mathrm{ppm}$. The amplitude of this difference cannot be explained by a single solution and needs to be further investigated. Marc Fisher and Dave Billesbach traveled to SGP to perform maintenance on the PGS in April.

\subsection{Cimel Sun Photometer}

Mentor: None (external data provided by NASA AERONET)

AMF (Heselbach) - Awaiting an upgraded, calibrated replacement (unit \#98). Unit \#168 will be returned to AERONET for upgrade and calibration.

NSA (Barrow) - The Cimel control box failed and had to be sent to AERONET for repair.

SGP (CF) - Operating nominally.

TWP (Nauru) - An EPROM with the corrected programming for unit \#402 has been sent to Nauru. It will be installed in August during the next RESET visit to Nauru.

\subsubsection{Internet Data Transfer}

The transfer of CSPHOT data from the Cimel instrument to AERONET using geostationary operational environmental satellite or Meteosat will be replaced with an Internet data transfer to improve reliability of the transfer, to permit ACRF personnel to monitor the transfer, and to allow the raw data to be acquired, ingested, and archived for use by ARM Science Team members (ECO-00555). Internet transfer of CSPOT data to AEORNET has been initiated at TWP-Nauru and SGP, and NSA-Barrow sites.

\subsection{Disdrometer}

Mentor: Mary Jane Bartholomew, Brookhaven National Laboratory

SGP - Operating nominally. $100 \%$ uptime in April.

TWP (Darwin) - Operating nominally. 100\% uptime in April. Darwin is entering the dry season. Only 1 rain event occurred in April where appreciable rain $(10 \mathrm{~mm})$ accumulated.

\subsection{Energy Balance Bowen Ratio Station}

Mentor: David Cook, Argonne National Laboratory

Data were generally good; however, problems with the automatic exchange mechanism (AEM) affected EBBR stations at six SGP extended facility sites in April. In preparation for CLASIC, four EBBR systems have been re-calibrated: two were installed in March and two more will be installed in early June.

Vaisala no longer supports the combined temperature and relative humidity probes in the EBBR (2 per system) but does still offer recalibration services. Replacement probes are available from the EBBR 
manufacturer. The mentor has proposed that replacement of all 32 probes be phased in over 3 years. As the old probes are replaced they can be used as spares for the systems not yet upgraded to the new probes.

\subsection{Eddy Correlation Station}

Mentor: David Cook, Argonne National Laboratory

AMF (Heselbach) - Operating nominally.

SGP - ECOR stations are operating nominally. Missing $\mathrm{CO}_{2} / \mathrm{H}_{2} \mathrm{O}$ data at E5 and E10 appear to be the result of damaged IRGA serial ports or the use of the wrong serial chip in the IRGA. Problems with the new optical isolators implemented to protect the ECOR computer serial ports during lightning have been traced to the serial driver chips in the infrared gas analyzers (IRGA). In preparation for CLASIC, several IRGAs were returned to the manufacturer for repair. Time keeping problems that occur following an unplanned shutdown of the ECOR computer have been addressed with a revised maintenance procedure and a script to update the BIOS clock every 24 hours.

\subsubsection{Add Wetness Sensors}

Periods of dew, frost, and precipitation often cause data from the $\mathrm{CO}_{2} / \mathrm{H}_{2} \mathrm{O}$ sensor and sonic anemometer to be incorrect. Adding a wetness indication would provide the data user with a more reliable source of information concerning this condition (ECO-00536).

STATUS - Wetness sensor testing on an ECOR system similar to the ARM ECORs began at Argonne in mid-Janary.

\subsection{G-Band (183.3 GHz) Water Vapor Radiometer}

Mentor: Maria Cadeddu, Argonne National Laboratory

The GVR is operating nominally. GVR data are now available from the ARM Archive (nsagvrC1.b1). Varying levels of RFI are observed in all four channels. Comparisons between measured and modelcalculated brightness temperatures are in good agreement.

\subsection{Global Positioning System (SuomiNet)}

Mentor: None (external data provided by SuomiNet/COSMIC)

Replacement receivers are in route to Manus and Darwin to preempt a failure due to the same problem experienced at Nauru.

SGP - Telecommunications problems continue to affect data availability from the SuomiNet stations: no data have been available from El Reno (E19) for several months. Wireless data communication equipment has been ordered for installation at E19. E12 data have been missing since 20 March; E27 was missing during April but has been restored; E3 has been missing since early May. All other SGP sites show gaps of 1-2 weeks in May.

TWP (Manus) - Operating nominally. 
TWP (Nauru) -The repaired GPS receiver was installed on 18 May.

TWP (Darwin) - Operating nominally.

NSA (Barrow) -Operating nominally using a spare ARM met system.

NSA (Atqasuk) - In June 2006 University Navstar Consortium personnel installed a GPS receiver at Atqasuk for geodetic purposes. A new GPS meteorological system will be connected to this receiver in June or July to permit the Atqasuk station to be incorporated into SuomiNet to provide precipitable water vapor data.

\subsection{In-situ Aerosol Profiling}

Mentor: John Ogren and Betsy Andrews, NOAA/ESRL/GMD

The Cessna 206 has returned to Ponca City from Wichita where the extended wingtips and MFR instrument were installed. Although the manufacturer repaired the high relative humidity nephelometer, it was damaged in shipment and was returned for repair again. Laboratory measurements suggest that the way relative humidity is controlled in the nephelometer could easily lead to water condensation in the instrument. This means that the setpoint humidity in both the medium and high relative humidity nephelometers could be significantly lower than the actual humidity in the two instruments.

The mentors plan to revisit their data editing and processing procedures, which will require reprocessing the IAP data later this summer. Currently the IAP data files sent to ARM don't include spectral absorption measurements in the segment averages. Also, the nephelometers may not have their zero correction applied properly.

\subsection{In-situ Carbon Profiling}

Mentor: Margaret Torn and Sebastien Biraud, Lawrence Berkeley National Laboratory

A continuous $\mathrm{CO}_{2}$ sampling system is scheduled to be added to the Cessna 206 aircraft prior to CLASIC in June. The continuous sampling system will supplement the 12-flask system already on the aircraft, which replaced a 2-flask system deployed on the earlier Cessna 172 aircraft since 2002.

\subsection{InfraRed Thermometer}

Mentor: Vic Morris, Pacific Northwest National Laboratory

InfraRed Thermometers (IRTs) have been deployed at 12 SGP extended facilities (ECO-345), operating at $5 \mathrm{~Hz}$ sampling rate. IRTs are also part of the SKYRAD and GNDRAD systems at TWP, NSA, and AMF. These are currently sampled at $0.5 \mathrm{~Hz}$. Efforts to increase the sampling rate of the SKYRAD IRTs to $5 \mathrm{~Hz}$ are in progress (ECO-00368). An ECR has been submitted to install the IRTs at NSA and TWP in ventilated enclosures similar to those in use at the SGP.

AMF (Heselbach) - Data were generally good.

NSA - Data were generally good. 
SGP - Data were generally good at most sites. The data were missing at E16 until 11 April. Higher sky temperatures were measured at E13 than both the AERI and the IRT at $\mathrm{C} 1$ because at low temperatures (below- $60^{\circ} \mathrm{C}$ ) the error due to the reflectance and temperature of the mirror becomes significant. Higher sky temperatures than at other facilities were measured at E19.

TWP - Data were generally good at all sites.

\subsection{Multi-Filter Rotating Shadowband Radiometer and Related Systems (MFR, GNDMFR, NIMFR)}

Mentor: Gary Hodges, NOAA/ESRL/GMDivision; John Schmelzer, Pacific Northwest National Laboratory

AMF - Operational at Heselbach.

NSA - MFRSRs, MFRs, and normal incidence multi-filter radiometers (NIMFRs) were re-installed in early April at Barrow and Atqasuk.

SGP -5 of 22 Extended Facilities do not have operational muti-filter rotating shadowband radiometers (MFRSRs).

TWP - Operating nominally.

\subsubsection{Multi-Filter Rotating Shadowband Radiometer Calibration and Data Processing Improvements}

Problems with the calibration and data processing of the MFRSRs were revealed during the ALIVE campaign (ECO-00571). New calibration processing will be implemented. Old data will be reprocessed to apply corrections and the new processing algorithms.

STATUS - MFRSRs with refurbished sensor heads and new data loggers are now operational at E2, E5, $\mathrm{E} 8$, and E13. Ingest processing is being finalized so data from these systems is not yet available from the Archive.

\subsubsection{Establish MFRSR Calibration Facility at SGP}

With the impending retirement of John Schmelzer, a facility for calibrating the MFRSRs is to be established at SGP. MFRSR calibration includes (1) cosine response characterization, (2) spectral bandpass characterization of the filter detectors, and (3) absolute (lamp) calibration. To establish the facility, the cosine bench and related items acquired by John Schmelzer at PNNL on behalf of ACRF will be relocated to the SGP Radiometer Calibration Facility (RCF) in May. Some modifications to the RCF may be necessary. Additional equipment will need to be acquired, including a monochromator and computer for performing the spectral characterizations. Joe Michalsky at NOAA GMD will be overseeing the task of establishing the facility as well as the routine calibrations to be performed using the 
facility. Joe will also direct other NOAA GMD staff to prepare documentation and train the SGP calibration technicians, and to review the resulting calibrations to ensure their validity prior to deployment in the field. (ECO-00617)

STATUS - The cosine bench and related equipment arrived at SGP and was installed by SGP personnel. John Schmelzer traveled to SGP during the week of 21 May to optically align the bench and train SGP technicians in the MFRSR calibration procedures.

\subsubsection{Data Logger Replacement}

The proprietary data loggers supplied with the MFRSRs and related instruments are to be replaced with Campbell Scientific CR1000 data loggers. This will permit them to be more easily maintained. It will also permit modifications to the operation of the instruments and data acquisition to be easily implemented (ECO-00350).

STATUS -MFRSRs with refurbished sensor heads and new data loggers are now operational at E2, E5, $\mathrm{E} 8$, and E13. Ingest processing is being finalized so data from these systems is not yet available from the Archive.

\subsection{Millimeter Cloud Radar}

Mentor: Kevin Widener, Pacific Northwest National Laboratory; Karen Johnson, Brookhaven National Laboratory

NSA/C1 - 100\% up time inApril.

$\mathrm{SGP} / \mathrm{C} 1-99 \%$ up time in April.

TWP/C1 (Manus) - 92\% up time in April. A new TWTA and coherent up/down converter (CUDC) will be installed in June.

TWP/C2 (Nauru) - 99\% up time in April.

TWP/C3 (Darwin) - 100\% up time in April.

\subsubsection{MMCR Processor Upgrades}

(ECO-00283) The spare PIRAQ-III processor will be installed in the MMCR at Darwin to replace the PIRAQ-III that failed. The NSA (Barrow) upgrade will be delayed until the failed processor is repaired or another spare is purchased.

STATUS - Vaisala reported that they were unable to find a problem with the failed boards from Darwin and is returning them to Kevin. Kevin will use these to upgrade the Barrow MMCR. 


\subsubsection{Add Polarization at Barrow}

(ECO-0052) Because the PIRAQ processor does not support polarization, the installation of the orthomode transducer at Barrow is on hold until the next processor upgrade.

\subsubsection{Spare Traveling Wave Tubes}

New TWT will be ordered to replace the TWTs originally delivered with the MMCRs, which are well beyond their rated lifetime and are beginning to fail (ECO-00425).

Both of the two spare TWTs ordered in the fall of 2006 have been received. Because the TWTs only have a 2-year lifetime, at least one more TWT needs to be ordered this year to permit the TWT at Darwin to be replaced in November 2007.

\subsubsection{Millimeter Wave Cloud Radar Spectra Processing}

Spectra files produced by the upgraded MMCRs (C40 or PIRAQ-III processors) range from 8 to 15 Gigabytes per day. Algorithms for eliminating clear-sky periods and compressing the files need to be developed and implemented locally (ECO-00391).

January 2007 - The compression algorithms have been implemented at SGP.

\subsubsection{Refurbish Millimeter Wave Cloud Radar Antennas}

Beginning in 2007, over a three-year period the MMCR antennas will be refurbished and characterized on an antenna range (ECO-00551). The spare antenna is complete and the contract for the new feed and subreflector has been placed. Once these are complete, they will be installed on the antenna reflector and calibrated. The Barrow MMCR antenna will most likely be refurbished first to avoid impacting planned IOPs and SGP.

STATUS - The Barrow MMCR antenna will be swapped with the spare antenna in August.

\subsubsection{Radome or Radome Dryer}

The detrimental effect on the data of standing water on the current fabric radome has prompted the pursuit of a more satisfactory solution. Unfortunately discussions with potential suppliers have not been fruitful. This taskis currently on hold (EC-00275).

\subsection{Micro-Pulse Lidar}

Mentor: Rich Coulter, Argonne National Laboratory

AMF - The new MPL at Heselbach is now operating nominally.

NSA - Operating nominally.

SGP - Operating nominally. 
TWP - The new MPL at Nauru is operating nominally. Replacing the laser diode at Darwin failed to resolve problems manifesting as thin, false cloud layers above $15 \mathrm{~km}$. The spare MPL at SGP was sent to Darwin to swap with this system, which will be returned to Sigma Space for inspection and repair.

\subsubsection{Modify MPL Polarization Switching and Data Acquisition}

Based on suggestions by Jim Spinhirne at NASA GSFC, the new spare MPL is to be modified as follows:

1. Switch polarizations between laser shots.

2. Use different data channels for each polarization. In combination with 1) this will permit essentially simultaneous 30 -second averages to be acquired for each polarization.

3. Use a 1/2-wave plate rather than a .-wave plate to acquire linear polarization directly.

STATUS - Prior to implementing these changes, a spare MPL will be loaned to Judd Welton and Tim Berkoff at NASA MPLNET for evaluation.

\subsection{MicroWave Radiometer}

Mentor: Maria Cadeddu, Argonne National Laboratory

Six MWRs were compared during October-November 2006: serial numbers 04, 10 (both from SGP/CF), 11 (SGP/B1), 12 (SGP/B5), 18 (SGP/B6), and 21 (NSA/C2). Differences of as much as $0.7 \mathrm{~K}$ in brightness temperatures at $23.8 \mathrm{GHz}$ (corresponding to $\sim 0.5 \mathrm{~mm}$ PWV) were observed between radiometers. In April, two of these radiometers (04 and 12) were sent to Radiometrics for diagnosis and repair. Radiometrics noted a positive bias of $1.2 \mathrm{~K}$ in the $23.8 \mathrm{GHz}$ channel of 04 compared to 12 and 51 (Radiometrics' reference unit). By adjusting the local oscillator drive voltage of 04 to optimize the mixer gain stability, the bias was reduced by $0.7 \mathrm{~K}$.

AMF (Heselbach) - Operating nominally.

NSA/C1 (Barrow) - Operating nominally.

NSA/C2 (Atqasuk) - Not in service. This radiometer (\#21) ws sent to the SGP central facility for inclusion in the MWR Inter-comparison IOP.

SGP-CF - Operating nominally.

SGP-E14 - The power supply failed in mid-March. This radiometer (\#04) has been sent to Radiometrics for inspection and repair.

SGP/B1 (Hillsboro) - Not in service. In October this radiometer was sent to the SGP central facility for inclusion in the MWR Inter-comparison IOP.

SGP/B4 (Vici) - No radiometer installed. In December 2005 the radiometer at Vici was sent to Darwin as a replacement for one damaged by lighting. 
SGP/B5 (Morris) - Not in service. This radiometer (\#12) has been sent to Radiometrics for inspection and repair.

SGP/B6 (Purcell) - In December this radiometer was sent to Manus to replace the failed MWR there.

TWP/C1 (Manus) - Operating nominally.

TWP/C2 (Nauru) - Operating nominally.

TWP/C3 (Darwin) - Operating nominally.

\subsection{MicroWave Radiometer Profiller}

Mentor: Maria Cadeddu, Argonne National Laboratory

AMF (Heselbach) - The K-band (22-30 GHz) brightness temperatures are about $2 \mathrm{~K}$ higher than model computations. The $30-\mathrm{GHz}$ channel is especially noisy with positive and negative spikes, possibly due to RFI. The V-band (51-59 GHz) channels are in good agreement with model computations. The drift in calibration of the K-band channels is reflected in the PWV retrievals that are slightly $(\sim 1 \mathrm{~mm})$ higher than the PWV retrievals using the MWR. LWP retrievals are slightly higher than the MWR retrievals as well.

NSA (Barrow) - Surface temperature readings were largely incorrect in April, which affects the profile retrievals primarily. The problem first appeared in February. A new "superblower" ordered from Radiometrics that has improved temperature and humidity sensors was installed in late April. K-band brightness temperatures are in good agreement with models; V-band measurements are in reasonably good agreement with models except for a drift in the $51.25 \mathrm{GHz}$ channel. This drift primarily affects the 6-channel LWP retrieval. The 2-channel LWP retrieval (using 23.825 and $30.0 \mathrm{GHz}$ channels) is in good agreement with the LWP from the MWR.

\subsection{Narrow Field of View Radiometer (NFOV)}

Mentor: None

The 2-channel NFOV radiometer has been installed at Heselbach.

\subsection{Raman Lidar}

Mentor: Rob Newsom, Pacific Northwest National Laboratory

The instrument's uptime for April 2007 was $93.5 \%$. The majority of the lost time was due to routine instrument maintenance activities and the installation of a new automatic alignment sensor.

During the installation of the new automatic alignment sensor in April a spider web was discovered on the tertiary mirror of the receiving telescope. The web was nearly impossible to see looking from the top of the telescope, which is why SGP technicians hadn't noticed it. Once the web was removed the received signal increased by $\sim 35 \%$, which is about the amount of the previously observed loss of sensitivity.

Analysis of raw signal returns indicates the presence of a relative shift of 8 range bins between the low analog and photon count rate signals. Prior to the installation of the new detection channels for 
temperature and liquid water on 27 October 2005 the relative shift was 3 range bins. The current version of RLprof_Merge uses a relative shift of 3 range bins between the analog and photon count rate signals, regardless of the date. As a result, all WFOV results collected after 27 October 2005 would be adversely affected by this assumption. The current version of RLprof_merge is being modified to properly account for this change in the relative shift.

Temperature profile retrievals are adversely affected by high solar background noise during the daytime. This is believed to be due to out-of-band leakage into the rotational Raman channel. Adding a wider band filter to block the leakage is being considered.

\subsubsection{Add Automatic Alignment System}

Due to small thermal gradients in the laser and the lidar enclosure, the alignment of laser beam in the detectors' field-of-view (FOV) changes with time, which can affect the data quality, sometimes substantially. To address this operationally, the laser beam is swept through the detectors' FOV using a pico-motor controlled steering mirror to find the optimal location. This "alignment tweak" is scheduled to occur every 3 hours. Accounting for the potentially 3 -hourly changes in alignments is the single largest uncertainty in the data processing codes. It affects all measurements, but the aerosol extinction measurements and the temperature profiles seem to be the most sensitive. Licel has recently developed a new product that permits the alignment of the lidar to be actively maintained (ECO-00586). The Licel alignment sensor was delivered in September.

STATUS - Rob Newsom, John Goldsmith, and Dave Turner successfully installed the new sensor in April.

\subsection{Rotating Shadowband Spectrometer}

\section{Mentor: Peter Kiedron, NOAA/ESRL/GMD}

The RSS is operating nominally. Field calibrations are nokminal. Automatic processing of calibration data is under development by Peter Kiedron and Jim Schlemmer.

Processed Langley data are available though January 24, 2007 at http://iop.archive.arm.gov/armiop/0special-data/asrc-rss/rss105/langley/. A comprehensive document on lamp calibration is available at: http://www.arm.gov/publications/tech_reports/handbooks/rss/manuals/

\subsection{Radar Wind Profiler - 915, $1290 \mathrm{MHz}$}

Mentor: Rich Coulter, Argonne National Laboratory

AMF (Heselbach) - The new $1290 \mathrm{MHz}$ system is now operating nominally.

SGP - Currently, all systems at SGP are operating nominally. The RASS at Meeker (IF3) is outof service due to a failed audio amplifier. During the installation of the $1290 \mathrm{MHz}$ RWP at Heselbach it was discovered that the output of moments data must be explicitly requested whereas formerly the moments were automatically output with the spectral data. As a result, no usable moments data were being produced from the central facility and Meeker systems between September 2006 and April 2007 when the configurations were corrected. 
NSA - System crashes frequently. The planned upgrade to new hardware, LAPXM software, and a new computer should help resolve this problem.

\subsubsection{Upgrade to Digital Receivers}

The four $915 \mathrm{MHz}$ RWPs at the SGP are now 9-13 years old and are exhibiting increasingly frequent, strange, and expensive-to-repair failures. Due to the age of these systems, parts are increasingly difficult to obtain. Vaisala offers an upgrade for these systems that will replace the present interface, receiver and computer (including DSP board) with new components and will include the latest version of LAPXM, the operating system. The systems at SGP/CF and SGP/I3 have been upgraded. The systems at SGP/I2, SGP/I3, and NSA/C1 will be upgraded in 2007 (ECO00567).

STATUS - The upgrade for the NSA system and the remaining two SGP systems have been ordered.

\subsection{Radar Wind Profiler - $\mathbf{5 0 ~ M H z}$}

Mentor: Rich Coulter, Argonne National Laboratory

In January 2006 the $50 \mathrm{MHz}$ RWP at the SGP ceased transmitting. The transmitter was returned to ATRAD in Australia for diagnosis and repair. After reinstalling the transmitter the output power was still zero. The transmitter has been shipped to Vaisala for diagnosis.

\subsection{Soil Water and Temperature System}

Mentor: John Harris, University of Oklahoma

Data are OK for most sites in April. Sites with one or more sensors needing replacement: E1, E5, E6, E8, E10, E13, E15, E16, E19, E20. New sensor arrays installed at E13, E19, and E20 last year will be activated after CLASIC concludes.

\subsubsection{Replace In-Ground Sensor Arrays}

New redundant sensor arrays will be installed at all SGP EF sites. These will be installed in a phased manner: 5 sites per year over the 4 years beginning in 2005 with the sites having multiple failed sensors given highest priority. After the soil recovers from the installation process in 6-12 months, the new sensor array will be connected to the existing SWATS data acquisition system in place of the old sensor array (ECO-00493).

STATUS - The new sensor arrays installed in May 2006 at E13, E19, and E20 will be connected after CLASIC concludes. Sensors for five more sites have been calibrated and will be installed after CLASIC concludes.

\subsection{Shortwave Spectrometer (SWS)}

Mentor: Scott Kittelman, University of Colorado

April had only a few clear sky days to analyze. Several broken cloud days during April produced signals that could be used for cloud edge analysis and cloud dynamics studies. In general, the Shortwave Spectrometer recorded many days with abundant cloud cover. This resulted in spectral data with large 
temporal variation. Due to the potential for hail-producing storms at SGP the protective cap was installed on the SWS light collector many times during April, which corresponds to a sudden and sustained drop to zero radiance. Typically the cap is installed late in the afternoon and removed early in the morning; however, because of predicted severe weather, the protective cap was installed for a 5-day period (12-16 April). Disk drive problems occurred several times during April. Problems with a temperature controller were diagnosed and corrected within a week.

\subsection{Surface Meteorological Instrumentation (SMET, SMOS, SURTHREF, THWAPS, MET, ORG, PWS)}

Mentor: Mike Ritsche, Argonne National Laboratory

AMF (MET, ORG) - Lens heaters were connected to remove the ice that was accumulating on the ORG and causing false readings. Electrical grounding issues are being investigated.

NSA (METTWR) - The Present Weather Sensor (PWS) at Barrow is providing erroneous readings. A complete re-calibration was done in May, but this failed to resolve the problems. A new receiver unit has been ordered.

SGP (SMOS) - All systems are operating nominally but with data gaps at E24 and E27. Wind monitor calibration checks are underway. (THWAPS) - Re-calibration was initiated in 2006. All sites except B5 have been calibrated.

TWP (SMET, ORG) - Most systems are operating nominally. At Manus of the redundant wind monitors failed in mid-March. The lower wind monitor at Nauru binds at low wind speeds.

\subsubsection{Develop Dynamic Rain Gauge Calibration Facility}

The tipping bucket rain gauges at the $15 \mathrm{SGP} / \mathrm{EF}$ sites with SMOS are currently calibrated using only a "static" calibration: a measured volume of water is poured into the gauge and the number of bucket tips is checked to ensure they correspond. In reality, as the rain rate increases and the bucket tips more frequently some rain is not collected. The purpose of the dynamic calibration is to determine the correction factor as a function of rain rate to account for this behavior (ECO-00495).

STATUS - Calibrations have been carried out for all SMOS tipping-bucket gauges.

\subsubsection{Upgrade T/RH Probes and Wind Sensors for NSA Met Systems}

Ice develops on the wind vanes, cup anemoneters, and aspirator inlets for the temperature and relative humidity sensors, which clog and affect the data quality. To alleviate these problems the mentor has proposed to replace the wind speed and direction sensors at NSA (both Barrow and Atqasuk) with sonic anemometers, and to replace the temperature and relative humidity probes with new, heated probes designed to operate in cold environments (ECO-00595).

STATUS - Replacement sensors are on order. 


\title{
2.30 Tandem Differential Mobility Analyzer
}

\author{
Mentor: Don Collins, Texas A\&M University
}

Data from the Tandem Differential Mobility Analyzer (TDMA) are currently acquired and processed by Don Collins. Processed data are then delivered to ACRF on a monthly basis and stored in the IOP area of the Archive as "beta-data." An ingest is being developed to produce netcdf files for inclusion in the main Archive (ECO-587).

\subsection{Hot Plate Total Precipitation Sensor (TPS)}

Mentor: Mark Ivey, Sandia National Laboratory

In late February and early March, the Hot Plate Total Precipitation Sensor indicated precipitation during periods when precipitation was not observed at the site or by other precipitation sensors nearby. Mark Ivey discussed this problem with the manufacturer. Yankee indicated that anomalous precipitation had been observed under cold conditions at other installations and an upgrade to the instrument's firmware was required. We are in the process of obtaining and installing that upgrade.

\subsection{Total Sky Imager}

Mentor: Vic Morris, Pacific Northwest National Laboratory

AMF - Operational at Heselbach.

NSA - The instrument has been reinstalled and is operational.

SGP - Operating nominally.

TWP - TSIs at Nauru and Darwin are operating nominally. Images at Manus and Nauru are occasionally hazy. Efforts to reduce moisture inside the camera housing continue.

New, improved mirror controllers are being developed by Ray Edwards at Brookhaven National Laboratory. (ECO-00625)

\subsection{Meteorological Tower Systems}

Mentor: David Cook, Argonne National Laboratory

60-m tower at SGP C1 (central facility) - nominal operation.

21-m tower at SGP E21 (Okmulgee) - nominal operation. Turkey vultures have been observed roosting on the wind speed/direction sensor.

40-m tower at NSA C1 (Barrow) - problems due to ice formation on temperature/humidity sensors and on the wind direction vanes continue. Replacement of these sensors with sonic anemometers and heated temperature/humidity probes has been proposed (ECO-00595).

SOWs have been prepared, quotes obtained, and Purchase Requisitions submitted for maintenance on the 60-m tower at SGP and the 40-m tower at NSA. SGP tower maintenance is tentatively scheduled for 2327 July; NSA tower maintenance is scheduled for mid-August. 


\subsection{Vaisala Ceilmeter}

Mentor: Vic Morris, Pacific Northwest National Laboratory

Data are generally good at NSA and SGP. Electronic ringing in the backscatter plot is visible at NSA-C2 (Atqasuk) and SGP-B5 (Morris, OK), but this does not affect the instrument's ability to detect clouds. Data were generally good at Manus, but the systems at Darwin and Nauru experienced reduced sensitivity to high clouds due to optical cross-talk problems. To address the optical cross-talk problems at TWP, the SGP units, which have "tropical" windows, will be swapped with the TWP units, which have "standard" windows.

\subsection{W-band (95 GHz) Atmospheric Radiation Measurement Program Cloud Radar}

Mentor: Kevin Widener, Pacific Northwest National Laboratory

AMF (Heselbach) - 97.3\% up time in April.

SGP - $100 \%$ up time in April.

In February 2008, following the deployment at Germany and prior to the deployment to China, the AMF WACR will be collocated with the SGP WACR for calibration.

\subsubsection{Study Network Transfer of MMCR and WACR Spectra to Archive}

ECO-00369 presents a mechanism to ship MMCR and WACR spectra data from measurement site to Archive by shipping hard drives. This requires significant costs in shipping of media, especially from the TWP Island sites, as well as significant staff effort to manage the relatively large number of disks and to implement the process at the sites and the Archive. This ECO proposes that we evaluate the feasibility of implementing data reduction algorithms (ECO- 00391) at each MMCR and WACR installation and that of shipping the resulting files to the Archive via Internet.

STATUS - A version of this software has been tested. Implementation is underway (BCR-1349). 


\section{Future Instrumentation Planning}

In this section instrumentation that have been proposed for future acquisition and discussed by the Science Team Working Groups - but not yet approved for purchase - are presented along with any status information.

\subsection{Future Microwave Radiometers}

The 2-channel MWRs range between 8-15 years old. They are no longer being manufactured. Warren Wiscombe and Eugene Clothiaux are organizing a workshop to discuss/determine ACRF's plans for future microwave radiometers. The workshop will be held in November, just prior to the joint meeting of the Cloud Properties and Cloud Modeling Working Groups.

\subsection{Atmospheric Radiation Measurement Program Volume-Imaging Array}

The ARM Volume-Imaging Array (AVA) is a proposed radar system to be deployed at the ARM SGP site to address the ARM program's need of mapping 3D cloud and precipitation structures at short to medium ranges (i.e., 20-75 km). The AVA system will provide time-resolved 3D precipitation fields, domain-averaged rainfall rate, cloud coverage throughout a volume, cloud-top heights, hydrometeor phase information (using polarization), horizontal and vertical variability of clouds and precipitation, and low-level convergence and divergence using dual-Doppler techniques. Principal elements of the AVA proposal prepared by Pavlos Kolias include:

- Three networked scanning radars arranged in a triangle with $20-30 \mathrm{~km}$ legs: one operating at $35 \mathrm{GHz}$ (same 8.6-mm wavelength as the MMCR) and capable of scanning the vertical region probed by the current MMCR, and two radars operating at $9.4 \mathrm{GHz}$ (3.2-cm wavelength, so-called "X-band"). All three radars will be transportable, scanning, polarimetric and Doppler.

- Development of a useful 3D cloud VAP similar to the existing ARSCL but on a regular 3D grid.

- Development of an "AVA Simulator." Patterned after the well-known International Satellite Cloud Climatology Program Simulator, the AVA Simulator will perform forward simulations of radar observables, using as input large-eddy simulation model and cloud-resolving model outputs of cloud properties together with the characteristics of the AVA radars. The results will be used to develop and optimize volumetric radar scanning strategies, develop and evaluate inverse retrieval techniques, and develop prototype 3D ARSCL-like VAPs for the ARM community.

- A collaborative effort with the Center for Interdisciplinary Remotely-Piloted Aircraft Studies (CIRPAS) to deploy the CIRPAS 9.4-GHz phased-array radar at the ARM SGP site every year for 1-2 months of continuous observations.

STATUS - Consideration of the AVA, as such, has been deferred until 2008 when simulations have been carried out to demonstrate its capabilities and further refine its requirements. 


\subsection{Absolute Scanning Radiometer}

To provide an absolute IR flux reference, which could be used to calibrate the Eppley PIRs, Ells Dutton has suggested that ARM develop an Absolute Scanning Radiometer (ASR). This instrument would be functionally equivalent to an ASR developed by Rolf Philipona for the WMO. This instrument would not be used for routine data acquisition, but instead would provide a calibration reference. As such it would participate in WMO inter-comparisons at Davos, Switzerland every five years. Although a SBIR solicitation for an ASR was issued circa 2000, no successful proposals were received. Ells Dutton, Tom Stoffel, and Joe Michalsky are planning to develop a specification so that ACRF may send out a request for proposals to identify interest and cost for such an instrument.

STATUS - In December 2006 a description of the desired instrument capabilities was published in Fed Biz Ops (solicitation number 111506). Based on the published description, Rough Order of Magnitude cost estimates have been received from several interested organizations.

\subsection{Portable Raman Lidar}

Leosphere http://www.lidar.fr/ offers a portable MPL-type lidar that can be augmented with Raman capability. Raymetrics http://www.raymetrics.gr/(sold by Kipp \& Zonen) also offers a Raman Lidar. Iwona Stachlewska of Leosphere deployed their non-Raman EZ Lidar at the SGP on 19 October for comparison with the ARM MPL system. Leosphere expects to have a commercial Raman system available in mid-to-late 2007. Raymetrics will not be able to furnish a demonstration Raman lidar system.

STATUS - Clarification of the scientific requirements for a portable Raman lidar is necessary before proceeding.

\subsection{High-Resolution Oxygen A-Band and Water-Band Spectrometer}

Qilong Min has submitted a proposal to build an A-band spectrometer for ARM. The 3-year proposal and budget were sent out for technical reviews. The technical reviews, along with the proposal and budget, were then provided to the Science Team Executive Committee. The Science Team Executive Committee directed Qilong to present his plan and budget to the Cloud Properties working group at their November 2005 meeting for prioritization. Qilong presented a revised work plan (water-band/cloud phase components removed) and has submitted a revised budget.

STATUS - At the 2007 ARM Science Team Meeting in Monterey Anthony Davis organized a discussion of the need for and possible approaches to providing A-band measurements at an ACRF field site.

\subsection{Rotating Shadowband Spectrometer Overhaul}

Peter Kiedron has demonstrated that the RSS built by YES is capable of providing valuable measurements of direct, diffuse, and global spectral irradiance. Peter has also identified problems with the RSS that affect the stability of its calibration and the linearity of its response. Peter has recommended that the RSS be removed from service and sent to him at SUNY-Albany for a complete overhaul. 


\subsection{Add 1.6 :m Channel to Multi-Filter Rotating Shadowband Radiometer and Narrow Field of View}

Alexander Marshak has recommended that ARM support the development of a NFOV radiometer at $1.6 \mu \mathrm{m}$ to permit the retrieval of droplet size distribution. Andy Lacis and colleagues have suggested a $1.6 \mu \mathrm{m}$ channel be substituted for the unfiltered (broadband) channel in the MFRSR. Because the unfiltered channel is now being used in a broadband radiometer best estimate Value-Added Procedure (VAP) for quality checking purposes, only a limited number of MFRSRs would be modified to accept a $1.6 \mu \mathrm{m}$ channel.

\subsection{Aerosol Particle Sizing Spectrometer to Replace Optical Particle Counter at Southern Great Plains}

John Ogren has suggested replacing the aging Optical Particle Counter included in the SGP AOS with a new Aerosol Particle Sizing Spectrometer to be integrated into the existing TDMA.

\subsection{Aerosol Particle Sizing Spectrometer (APS) to Replace Optical Particle Counter (OPC) at SGP}

John Ogren has suggested replacing the aging OPC included in the SGP Aerosol Observing System (AOS) with a new APS to be integrated into the existing TDMA.

\subsection{Infrared Thermometers for the Southern Great Plains Extended Facility Sites}

Six IRTs were purchased in FY 2004, 9 additional IRTs were purchased in FY 2005. Some of these have been deployed with the AMF. Twelve SGP EF sites are currently equipped with IRTs; 10 additional IRTs would be needed to permit an IRT to be deployed at all 22 SGP extended facilities. 


\section{Small Business Innovation Research}

The DOE SBIR web page is at http://www.er.doe.gov/sbir/

\subsection{Eye-Safe Ultraviolet Backscatter Lidar for Detection of Sub-visual Cirrus (FY 2006)}

Based on recommendations from the 2004 Cloud Properties working group meeting, this subtopic was substituted for the A-band spectrometer subtopic. Connor Flynn is the technical contact. Phase I funding was awarded to Aculight Corporation: "Eye-Safe ultraviolet Backscatter Lidar for Detection of SubVisual Cirrus" http://www.science.doe.gov/sbir/awards abstracts/sbirsttr/cycle24/phase1/039.htm

and to Physical Sciences, Inc.: "Field-Worthy ultraviolet Backscatter Lidar for Cirrus Studies." http://www.science.doe.gov/sbir/awards abstracts/sbirsttr/cycle24/phase1/044.htm

\subsection{Instrumentation for Remotely Sensing Aerosol Optical Properties - Aerosol Phase Function (FY 2006)}

Based on recommendations from the Aerosol working group, this subtopic was added to the aerosol measurements subtopic. Phase I funding was awarded to Aerodyne Research, Inc.: "CAPS-Based Particle Single Scattering Albedo Monitor."

http://www.science.doe.gov/sbir/awards abstracts/sbirsttr/cycle24/phase1/040.htm

\subsection{Unmanned Aerospace Vehicle-Suitable Cloud Radar (FY 2006)}

Phase I funding was awarded to ProSensing, Inc: "High-Power, Pod-Mounted W-band Cloud Radar for Unmanned Aerospace Vehicles (UAV)."

http://www.science.doe.gov/sbir/awards_abstracts/sbirsttr/cycle24/phase1/045.htm

\subsection{In-situ Measurement of Cloud Properties with Large Sample Volumes (FY 2007)}

Warren Wiscombe contributed the following sub-topic and will be the technical contact.

The DOE ARM Program was formed to study the climatic effects of clouds. These effects, particularly how clouds respond to climate change (the so-called "cloud feedback" problem), are large yet poorly understood from both a measurement and modeling point of view (cf. Stephens 2005). Currently, there is a huge gap in spatial scale between in-situ measurements of cloud properties, typically from aircraft and balloons whose instruments have sample volumes on the order of cubic centimeters, and remote sensing retrievals of cloud properties, which have sample volumes ranging from tens of cubic meters (radar and lidar) to thousands of cubic meters (satellites). Most acute is the fact that in-situ measurements at a particular point give no information on the vertical distribution above and below that point, while active remote sensing retrievals typically give instantaneous vertically-resolved information. Since clouds are inhomogeneous down to centimeter scales, there is a complete lack of comparability between in-situ 
measurements and remote retrievals; simple assumptions of homogeneity to scale up the in-situ measurements are certainly false. Clouds also evolve considerably in the course of a minute, and thus methods, which are slow in time (such as a balloon ascending, or an aircraft ascending or descending) fail to capture the instantaneous state which remote sensing sees. Thus, there is a great need for in-situ measurements which have fast vertical reach and much larger sample volumes, ranging from cubic meters to hundreds of cubic meters, in order to allow meaningful comparisons with surface and satellite retrievals of cloud properties. Without confidence in those surface and satellite retrievals, which are our only way to extend our reach to the whole planet, it is impossible to make progression key global change issues concerning cloud feedbacks on global warming.

Therefore, grant applications are sought to develop instruments to measure cloud properties in-situ, for scales ranging from cubic meters to hundreds of cubic meters, with particular emphasis on fast vertical profiling above and below the in-situ platform. (The platform need not be a traditional aircraft or balloon; instruments for small UAVs, kites, gliders, and tethered balloons will also be considered.) An example of such an instrument can be seen in Evans et al. (2003). Measurements of the following cloud properties are particularly wanted, in order of decreasing priority for cloud-climate applications: (a) extinction coefficient at one or more wavelengths in the solar spectrum away from strong water vapor absorption bands; (b) total water content (liquid plus ice); (c) liquid and ice water content separately; (d) effective radius, defined as the ratio of the $3^{\text {rd }}$ to the $2^{\text {nd }}$ moment of the drop size distribution; (e) absorption coefficient or single-scattering albedo at one or more wavelengths in the solar spectrum away from strong water vapor absorption bands; (f) the scattering phase function for ice clouds; ( $g$ ) the drizzle and precipitation fraction of the total condensed water content; (h) the supersaturation; (i) the dispersion, a measure of the width of the drop size distribution.

Stephens, G. 2005. "Cloud feedbacks in the climate system: A critical review." Journal of Climate 18:237-273.

Evans, KF. 2003. "In situ cloud sensing with multiple scattering lidar: Simulations anddemonstration." Journal of Atmospheric and Oceanic Technology 20:1505-1522. 